\title{
THE LATEST DTM USING INSAR FOR DYNAMICS DETECTION OF SEMANGKO FAULT-INDONESIA
}

\author{
Atriyon JULZARIKA (1) $1,2^{*}$, Trias ADITYA ${ }^{1}{ }^{1}$, Subaryono SUBARYONO ${ }^{1}$, \\ Harintaka HARINTAKA (D) 1 \\ ${ }^{1}$ Department of Geodetic Engineering, Universitas Gadjah Mada (UGM), Yogyakarta, Indonesia \\ ${ }^{2}$ Indonesian National Institute of Aeronautics and Space (LAPAN), Jakarta, Indonesia
}

Received 02 May 2020; accepted 17 August 2021

\begin{abstract}
The latest Digital Terrain Model (DTM) is seen as an upgradable DTM that is fitted to the latest combination of DTM master and its displacement. The latest DTM can be used to overcome the problem of static DTM weaknesses in displaying the latest topographic changes. DTM masters are obtained from InSAR and Digital Surface Model (DSM) ALOS PALSAR conversions. Meanwhile, the displacement is obtained from Sentinel-1 images, which can be updated every 6-12 days or at least every month. ALOS PALSAR data were the images acquired in 2008 and 2017, while Sentinel-1 data used were images acquired in 2018 and 2020. This study aims to reveal the importance of an upgradable DTM so called latest DTM which is combination of DTM master and its displacement in order to show the latest condition of study area. The case study is the dynamics analyze of the Semangko fault specifically in the Sianok and Sumani segments situated in Indonesia. The vertical accuracy assessment was done to evaluate the DSM to DTM conversion with a tolerance of $1.96 \sigma$. The result obtained is the latest DTM. It is derived from the integration of the DTM master with displacement. The latest DTM can be used to detect the dynamics of Semangko fault. The study area has vertical deformation at a value of $-50 \mathrm{~cm}$ to $30 \mathrm{~cm}$. The Semangko fault area is dominated by -25 to $5 \mathrm{~cm}$ deformation. In general, this region has decreased. The decline in this region ranges from $7.5 \mathrm{~cm}$ to $10 \mathrm{~cm}$ per year. The latest DTM vertical accuracy is $2.158 \mathrm{~m}$ ( $95 \%$ confidence level) with a scale of $1: 10,000$ to $1: 20,000$.
\end{abstract}

Keywords: the latest DTM, InSAR, ALOS PALSAR, Sentinel-1, Semangko fault.

\section{Introduction}

Digital Elevation Model (DEM) is a 3D model that describes topographical and bathymetrical conditions. DEM can be developed from various data sources, including topographic maps, field measurement data, photogrammetry, interferometry, sonar, and satellite imageries (Maune \& Nayegandhi, 2018). Several methods can be used for DEM extraction, namely Triangular Irregular Network (TIN), stereo, interferometry, LiDAR, videogrammetry, and DEM integration (Julzarika \& Djurdjani, 2018). Hence, the different methods applied to a similar data source can produce different results, and therefore an evaluation of this technique's comparative suitability is needed (Wang et al., 2015).

The commonly known form of DEM is the Digital Surface Model (DSM) and Digital Terrain Model (DTM) (Maune \& Nayegandhi, 2018). DSM mainly describes the surface of vegetation, building, and open land, while DTM presents information regarding rivers, contours, and features that exist in nature without vegetation surfaces and building surfaces (Hirt, 2014; Li et al., 2004). In other words, the DTM functions to describe 3D conditions at ground level or topography (Krauß et al., 2011), and it can be used for modeling applications, contour generation, orthorectification, and others (Maune \& Nayegandhi, 2018).

DSM and DTM have been developed and applied for various purposes. However, most of them are static. They display only the past condition, which neither represents the current condition nor uses the deformation parameter related to topographic changes. Factor attributed to these problems includes the availability of raw data, expensive processing costs, and the relatively long time to process (Monserrat et al., 2014). Examples of static DTM are Shuttle Radar Topographic Mission (SRTM), X SAR, ALOS PALSAR. The weaknesses the static DTM can be improved by the latest DTM, which accommodates the latest condition of the topographic changes. The latest DTM is seen as

${ }^{*}$ Corresponding author. E-mail: verbhakov@yahoo.com

Copyright @ 2021 The Author(s). Published by Vilnius Gediminas Technical University

This is an Open Access article distributed under the terms of the Creative Commons Attribution License (http://creativecommons.org/licenses/by/4.0/), which permits unrestricted use, distribution, and reproduction in any medium, provided the original author and source are credited. 
an upgradable DTM that is fitting to the latest combination of DTM master and its displacement.

According to former literatures, it has been reported three extraction of DSM and DTM (i.e., two products of DEM can be done using three methods (Krauß et al., 2011), namely (1) the classical morphological approach (Weidner \& Förstner, 1995), (2) geodesic dilation (Arefi et al., 2009), and (3) steep edge detection (Krauß \& Reinartz, 2007). The latest DTM proposed here is extracted from the development of a combination of the classical morphological approach and geodesic dilation methods. The morphological approach is made by the DSM to DTM conversion with the help of Interferometric Synthetic Aperture Radar (InSAR), while geodesic dilation is carried out in the interferometry processing and displacement calculation using Differential InSAR (DInSAR).

Satellite imagery was chosen because it has better temporal resolution, relatively inexpensive mapping costs, adequate accuracy on a scale of 1:10,000 to $1: 20,000$, and requires a relatively short time (Bakon et al., 2014; Krauß et al., 2011; Krauß \& Reinartz, 2007). Naidoo et al. (2016) use ALOS PALSAR imagery in their research related to using the L band to calculate tree canopies. A study to estimate the correlation between land subsidence and groundwater extraction was conducted by Du et al. (2018).

Land subsidence is characterized by vertical deformation. In this case, the horizontal movement map derived from Sentinel-1 confirms that vertical displacement is dominant when viewing from the Line of Sight (LOS). Further analysis carried out at various scales shows that industrial groundwater use is not always the dominant factor causing land subsidence and does not create significant changes. Areas that experience subsidence was caused by the combined impact of several factors, such as housing, industrial, or agricultural activities. This result shows the efficient use of satellite-based monitoring networks to develop disaster mitigation plans. High precision DEM extraction based on image orbit parameters was studied by Xin et al. (2018) in which their advanced method is useful in getting precision DSM. The method takes into account metadata from satellite imagery.

In Indonesia, the fusion of IFSAR data, ALOS PALSAR, TanDEM-X, X SAR, and SRTM had been extracted to develop national DEM so-called DEMNAS covering Indonesia area in 2010 (Badan Informasi Geospasial [BIG], 2019). However, most areas of DEMNAS are still in the form of DSM, especially for areas outside Java island, which is not optimal for detailed mapping applications. Even in Java, the most populated island, the condition of DEMNAS is mixed between DSM and DTM (Julzarika \& Harintaka, 2020).

The research aimed to reveal the importance of an upgradable Digital Terrain Model (DTM) so called latest DTM which is combination of DTM master and its displacement in order to show the latest condition of study area. The case study is the dynamics analyze of the Semangko fault specifically in the Sianok segments and Sumani segments situated in Indonesia. The latest DTM is the proposed solution to overcome the problem such as static DTM weaknesses in displaying the latest topographic changes. Located between the dynamic Eurasian and Australian plates and in the Pacific Ring of Fire, the area is prone to natural disasters. The Semangko Fault area is an area with high vertical deformation conditions. This condition makes the availability of the latest DTM with the satisfactory quality necessary to support rapid mapping required in disaster management. Specifically, this study aims to detect the dynamics of Semangko fault with the latest DTM extracted from ALOS PALSAR and Sentinel-1.

The latest DTM is extracted from the development of a combination of the classical morphological approach and geodesic dilation methods. The morphological approach is made by the DSM to DTM conversion, while geodesic dilation is carried out in the interferometry processing and displacement calculation.

\section{Study area}

The location of this research is in Semangko fault. Semangko fault is along the Sumatra island, Indonesia (Julzarika \& Harintaka, 2019). This fault stretches from Aceh to Semangka Bay in Lampung. This fault forms the Bukit Barisan (Barisan Mountains). Semangko fault can be seen directly in the Sianok canyon and Anai Valley, West Sumatra province. This fault is sliding. It like the San Andreas Fault in California. The area through which the Semangko fault often experiences large earthquakes.

The Semangko fault had formed when the IndianAustralian Plate (Ocean) crashed across the western part of Sumatra, which was part of the Eurasian Plate (Continent) millions of years ago (Hurukawa et al., 2014). This collision triggers the appearance of two force components. The first component is perpendicular, dragging the tip of the Indian Plate under the Sumatra Plate. The boundary

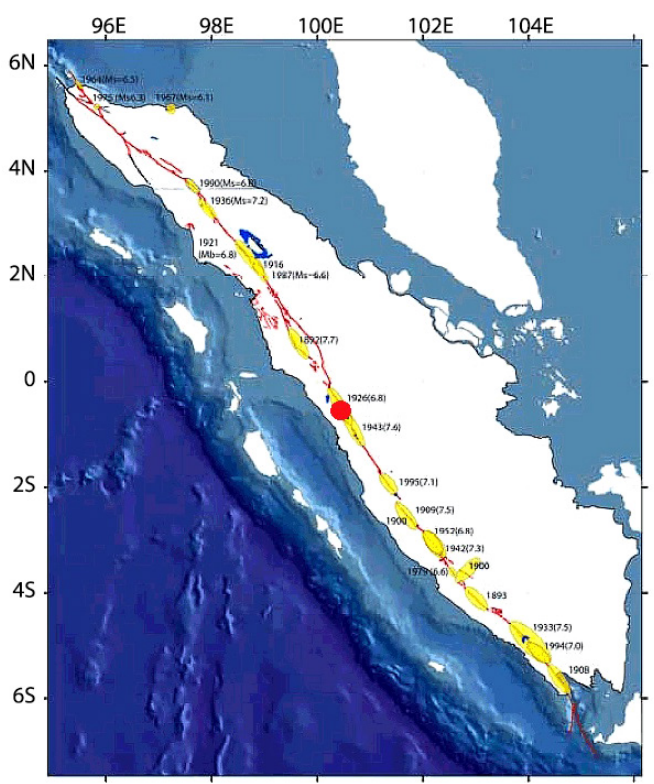

Figure 1. Semangko fault and Sianok-Sumani segment (Geological, 2017). The red circle is the research area 
of these two plates is up to a depth of $40 \mathrm{~km}$ and is tightly attached. The accumulated pressure cannot be held so that it produces an earthquake centred around the subduction zone. After that, the contact area will glue again until one day, and a massive earthquake occurs again. Earthquakes in zones often trigger tsunamis, such as in Aceh on December 26, 2004. The second component is a horizontal force parallel to the trough and drags the western part of the island to the northwest. This force creates longitudinal cracks parallel to the plate boundary, known as the Sumatra fault (Semangko fault) (Hurukawa et al., 2014), see Figure 1.

Katili geologist in The Great Sumatran Fault (1967) states that these cracks formed in the Middle Miocene period, 13 million years ago (Katili, 1967). In Semangko fault, the west plate moves northwest at a speed of $10 \mathrm{~mm} /$ year to $30 \mathrm{~mm} /$ year. It is relative to the eastern part of that fault. The Semangko fault field is a subduction zone to a depth of 10 to $20 \mathrm{~km}$ and is locked so that the pressure accumulation occurs. The accumulated pressure has increased so that the contact area in the fault zone cannot withstand and then rupture. The rock on either side suddenly bounced strongly so that a massive earthquake occurred. After an earthquake, the fault will reattach and lock again and gather elastic pressure until one day, another major earthquake occurs (Socquet et al., 2019).

The epicenter in Sumatra's fault was generally shallow and close to settlements. The impact of the energy released can be felt very hard and is usually very damaging. Moreover, earthquakes in the fault zone are always accompanied by horizontal movements that cause cracks in the ground, which will knock down buildings. The topography along the fault zone, which is surrounded by the Bukit Barisan, often triggers landslides (Natawidjaja, 2018).

Most of the dextral (or right-spinning) components of the oblique crust's convergence or collision are between the Asian Crust and the Indo-Australian Crust. The Semangko fault has a length of $1900 \mathrm{~km}$. This fault is very active and in the form of a sliding fault (strike-slip). This fault zone stretches along the western side of the Sumatra island. The Sumatra fault is highly segmented and consists of 20 main defined geometric segments. Each segment has a length of around 60 to $200 \mathrm{~km}$. The length of this segment is affected by the dimensions of the earthquake source. It has been divided into shorter faults that historically have caused earthquakes with a strength between 6.5 to over $9 \mathrm{Mw}$.

The latest DTM will be tested in Semangko fault, specifically in the Sianok segments and Sumani segments. The Sianok segment extends from the northeast side of Lake Singkarak, past the Southwest side of Mount Marapi to the Sianok Canyon. Lake Singkarak is a tectonic lake. The segment length of $90 \mathrm{~km}$ with the maximum earthquake potential in this segment is $7.3 \mathrm{Mw}$. The Sumani segment is located around Lake Singkarak. The north end of this segment is on the north side of Lake Singkarak, goes along the southwestern side of the lake across the Solok City,
Sumani, Selayo area, and ending at the north of Lake Diateh, southeast of Mount Talang. The length of the $90 \mathrm{~km}$ segment with a potential of $65 \mathrm{~km}$ strong earthquake in this segment is $7.2 \mathrm{SR}$. In addition to these earthquakes, local earthquakes are also frequent regularly so that monitoring is needed quickly, effectively, and efficiently. The latest DTM is proposed as a solution to overcome this problem.

\section{Data and methodology}

\subsection{ALOS PALSAR and Sentinel-1}

Data in this research are ALOS PALSAR and Sentinel-1. In order to do so, the data of three satellites in two different time slots have been taken into account: ALOS PALSAR in 2008, ALOS PALSAR2 in 2017, and Sentinel-1 in the years 2018 and 2020. DSM is extracted from the ALOS PALSAR and ALOS PALSAR2. The InSAR method is used to extract the DSM. The DInSAR method is used to extract the displacement, and then it is integrated with the DSM from the data 2008. The DInSAR 2017 is extracted from ALOS PALSAR-2. The Sentinel-1 data is used to extract dynamic displacement. The Sentinel-1 data used is the acquisition of 2018 and 2020. ALOS PALSAR in level 1.0 format or raw data. Sentinel-1 data in processed level 1 Single Look Complex (SLC) data and Interferometric Wide Swath (IW) mode. ALOS PALSAR using the L band while the Sentinel-1 using the $C$ band. This research using single-polarization for ALOS PALSAR and dual-polarization for Sentinel-1.

ALOS PALSAR is a Japanese SAR satellite that has optimal capabilities in DSM extraction (Alganci et al., 2018; JAXA, 2008; Naidoo et al., 2016; Strozzi et al., 2018). This first generation of ALOS PALSAR has been operating from 2006 until 2011. Then the ALOS program was resumed with the ALOS PALSAR-2 generation from 2015 until now. ALOS PALSAR is a radar satellite that carries a PALSAR sensor with a spatial resolution of 6.25 to $18 \mathrm{~m}$. The PALSAR sensor has an off-nadir capability that is variable between 10 to 51 degrees with active phased array techniques with 80 modules to transmit/receive (EORCJAXA, 2021). PALSAR sensor is a fully polarimetric instrument, working with one of the modes, namely single polarization $(\mathrm{HH}$ or $\mathrm{VV})$, double polarization $(\mathrm{HH}+\mathrm{HV}$ or $\mathrm{VV}+\mathrm{VH})$, or full polarization $(\mathrm{HH}+\mathrm{HV}+\mathrm{VH}+$ $\mathrm{VV})$. Viewpoints are variable between 7 and 51 degrees (angle of arrival 8 to 60 degrees), averaged at 34.2 degrees (EORC-JAXA, 2021).

The Sentinel Satellite is a natural resource satellite owned by the European Space Agency [ESA]. This satellite consists of radar and multi optical satellites. This satellite has a temporal resolution of 6 to12 days. Sentinel $1 \mathrm{~A}$ and Sentinel $1 \mathrm{~B}$ are SAR satellites with C band (ESA, 2019). The $C$ band instrument can measure land subsidence or vertical deformation using InSAR imagery. The phase difference analysis uses two or more SAR images so that it can produce DSM and deformation. Sentinel-1 has 
a spatial resolution of 5 to $20 \mathrm{~m}$ and a temporal resolution of 6 to 8 days. It will be able to improve the InSAR technique in providing systematic data continuity.

Sentinel-1 has four operational modes: Strip Map (SM), Interferometric Wide Swath (IW), Extra Wide Swath (EW), and Wave (WV). SM Mode features $5 \times 5 \mathrm{~m}$ spatial resolution and $80 \mathrm{~km}$ swath. The sole uses of SM are to monitor small islands and emergency management for extraordinary events. It offers data products in a single $(\mathrm{HH}$ or $\mathrm{VV})$ or doubles $(\mathrm{HH}+\mathrm{HV}$ or $\mathrm{VV}+\mathrm{VH})$ polarization (ESA, 2019).

IW mode features 5 to $20 \mathrm{~m}$ in spatial resolution and a $250 \mathrm{~km}$ swath. IW is the primary operational mode over land. IW accomplishes interferometry through burst synchronization. IW offers data products in a single $(\mathrm{HH}$ or $\mathrm{VV})$ or doubles $(\mathrm{HH}+\mathrm{HV}$ or $\mathrm{VV}+\mathrm{VH})$ polarization. $\mathrm{EW}$ mode features 25 to $100 \mathrm{~m}$ spatial resolution and $400 \mathrm{~km}$ swath (ESA, 2019). EW is used to monitor the phenomena of vast coastal areas. These phenomena are shipping traffic and potential environmental hazards. It offers data products in a single $(\mathrm{HH}$ or $\mathrm{VV})$ or doubles $(\mathrm{HH}+\mathrm{HV}$ or $\mathrm{VV}+\mathrm{VH}$ ) polarization. WV Mode features 5 to $20 \mathrm{~m}$ in spatial resolution and a low data rate. It produces $20 \times 20 \mathrm{~km}$ sample images along the orbit at intervals of $100 \mathrm{~km}$. This mode is the primary operational mode over the open ocean. WV offers data products only in single (HH or VV) polarization (ESA, 2019).

\subsection{Interferometric Synthetic Aperture Radar (InSAR)}

InSAR is a remote sensing technology that uses radar images from aircraft or satellites (Lusch, 1999). Interferometry steps include the interferogram generation, adaptive filter and coherence, phase unwrapping, refinement and re-flattening, phase to height conversion, and geocoding (Ng et al., 2017).

The first step is the interferogram generation. In interferogram generation, the distance difference between sensor position on the two acquisitions and a point on the Earth can be measured by the phase difference $(\phi)$. This phase between two complex co-registered SAR images (Pieraccini \& Miccinesi, 2019). This phase is performed by multiplying one image by the complex conjugate of the other one, where an interferogram is formed. Adaptive filter and coherence aim is to do the filtering of the flattened interferogram and enable it to generate an output product with reduced phase noise (Arai, 2019). The interferometric coherence, which is an indicator of the phase quality and the master intensity filtered image generation.

In phase unwrapping, the interferogram phase can only be modulo $2 \pi$; hence, anytime the phase change becomes larger than $2 \pi$, the phase starts again, and the cycle repeats itself. The fringe orientation angle modulo $2 \pi$ is a crucial point for the phase's robust demodulation from a single fringe pattern (Quiroga et al., 2002). Phase unwrapping is the interferometry process that resolves this
$2 \pi$ ambiguity (Liu et al., 2011). Some phase unwrapping algorithms are the branch-cuts, region growing, minimum cost flow (Costantini, 1998), minimum least squares, and multi-baseline. All of these methods have not been able to get optimal results (Liu et al., 2018).

The next step of interferometry is refinement and reflattening (Lesko et al., 2018). This step is crucial for transforming the unwrapped phase information into height and displacement values (Li \& Kuai, 2014). It allows both to refine the orbits and calculate the phase offset or remove possible phase ramps. Phase to height conversion and geocoding are the last steps for DSM extraction using InSAR (Zuo et al., 2016). The absolute calibrated and unwrapped phase is in the synthetic phase combination. It is converted map projection from the height and geocoded. This step is similar to the geocoding procedure. It is considered by the Range-Doppler approach and the related geodetic and cartographic transforms (Wang et al., 2014). The difference between the geocoding step is the RangeDoppler equations. They are applied simultaneously to the two antennae. The geocoding makes it obtain not only the height of each pixel but also its location (easting, northing) in a given cartographic and geodetic reference system (Du et al., 2018; Nahli et al., 2018).

Phase to displacement conversion and geocoding is one of the interferometry steps for deformation applications (Cuevas-González et al., 2018). The absolute calibrated and unwrapped phase values are converted to displacement and directly geocoded into a map projection (Dai et al., 2016). These steps are performed in a similar way as in the geocoding procedure. It considers the Range-Doppler approach, cartographic transform, and the related geodetic (Dammann et al., 2016).

\subsection{Displacement}

Deformation referred to in this paper is a displacement of the vertical direction (1D). Vertical direction shift occurs in tectonic regions with dip-slip faults (Passchier \& Trouw, 2005). Geodynamics is related to tectonics, related to the formation of faults and earth's plates. In general, geodynamics is a science that studies the transfer of material that exists on earth due to the rock deformation process, which is plastic, elastic, and brittle.

According to Turcotte and Schubert (2014), geodynamics is studying fundamental physical processes for understanding plate tectonics and various geological phenomena. Geodynamics relates to changes in the part of the earth caused by force triggered by the energy that comes from within the earth (Koukouvelas et al., 2018). Magma is an example of geodynamics. Geodynamics include volcanism, lithospheric motion due to convection currents, earthquakes, motion formation basins, sedimentation, and mountains.

The high deformation region is the deformation region with a high voltage loading rate. Areas with high deformation have high voltage loading rates or high geodynamic and deformation conditions, change rapidly, often occur 
natural disasters, and occur in areas with plates and faults (Passchier \& Trouw, 2005).

In this study, the method's application was carried out in Semangko Fault, northern Lake Singkarak. The selection of areas with high geodynamics is useful in using the latest DTM by considering significant deformation parameters. These deformation parameters can include horizontal deformation, vertical deformation, and mixed deformation. In this research, the study area generally experienced a vertical shift or displacement. During this time, a current displacement event in Indonesia is in vertical deformation (Julzarika \& Rokhmana, 2019).

\subsection{DSM to DTM conversion}

DTM is extracted from the DSM conversion results (Pirotti, 2010; Zhang et al., 2016). This conversion uses the tree offset approach, height error correction, and geoid undulation correction (Raaflaub \& Collins, 2006). Another thing that plays an important role in getting DTM with high accuracy and precision in determining the method of converting DSM to DTM (Gallant et al., 2012; Krauß, 2018) researched how to correct height errors and convert DSM to DTM on SRTM and other DSM data. The main parameters in the DSM conversion use vegetation, namely vegetation coverage (tree cover), vegetation height offset, and the angle of the slope of the tree canopy.

The method for removing tree offsets depends on the presence or absence of trees from satellite imagery, and the offset height is calculated from the DEM in the tree boundary plane (Bigdeli et al., 2018). Tree offset is estimated near each edge of the patch with the least-squares estimate based on local height variation models (Gallant et al., 2012). The reduction of offset from DSM is to produce DEM. Interpolation of tree offsets is multiplied by smoothed tree cover maps. It aims to produce estimates of tree offset that can be deducted from DSM to produce DEM of vacant land (Moudrý et al., 2018). Estimates of tree offsets depend on accurately identifying object heights in topography that are not covered by the tree. DSM registration and land cover will result in lower tree offset estimates. Offsets that experience height errors need to be removed to be effective in converting DSM to DTM (Champion \& Boldo, 2006).

The response of DSM SRTM to changes in tree cover is not sharp, but the transition is smooth at a distance of 3 to 4 pixels (about $100 \mathrm{~m}$ ) (Gallant et al., 2012). This smooth transition must be taken into account in offset correction to avoid artefacts around the tree cover patches. The artefacts are similar to a height error in DEM (Gallant et al., 2012). Error correction is required to remove error errors. Estimates of true tree offset depend on accurate identification of the transition location from open terrain to treecovered terrain (Gallant et al., 2012).

Height errors are random errors in the form of blunders that occur due to anomalies of height value on the eight closest neighbors (Julzarika, 2015). The height error correction needs to be done on a DEM of various input data. The height error correction aims to eliminate height value anomalies that are different from eight surrounding neighbors, blunders, and give rise to incorrect contour conditions. Height error correction is done by three existing methods, namely Fill Sink, Cut Terrain, and Height Error Maps (HEM) (Julzarika, 2015).

The geoid is a model of the earth that is approaching the real or equipotential plane, which coincides with the surface of the sea in a calm and uninterrupted state (Bayoud \& Sideris, 2003). Geoid practically is considered coincide with mean sea level (Mean Sea Level (MSL)) (Hofmann-Wellenhof \& Moritz, 2006). World Gravity Map (WGM) 2012 is a 3D gravity model with a highresolution grid and anomalous maps of Earth's gravity (Bouguer, isostatic and free air surface), calculated on a global scale in spherical geometry (Bonvalot et al., 2012).

\subsection{Research methodology}

The methodology behind this work is divided into three distinct phases: pre-DTM processing, DTM processing, and post-DTM processing. The research flow-chart can be seen in Figure 2. In pre-DTM processing, using InSAR images of ALOS PALSAR and ALOS PALSAR2, DSM is extracted from the data of two separate years. On the other hand, with the help of DInSAR techniques, dynamic displacement can be obtained by Sentinel-1 imagery. Meanwhile, displacement can be updated every 6 to 12 days or at least one month depending on requirements.

In the next step, DSM will be converted to DTM, called DTM master. DTM master is a DTM that is used as a reference in making the latest DTM. Afterwards, DTM master is integrated with displacement created by Sentinel images in the previous step. Finally, the accuracy is assessed prior to creation of latest DTM. Accuracy assessment is the step to know the accuracy value of DTM. The final result is the latest DTM. The results obtained are the corrected DTM or after this referred to as DTM master.

InSAR is used to extract the DSM. DInSAR is used to extract the displacement. DSM must be converted to be DTM, called DTM master. This DTM master is integrated

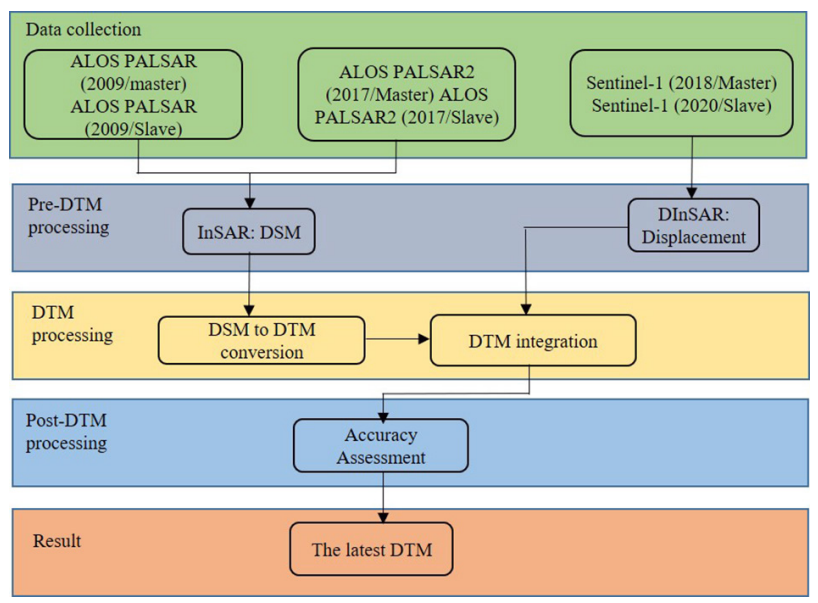

Figure 2. Research flow-chart 
with displacement. Accuracy assessment is the step to know the accuracy value of DTM. The final result is the latest DTM.

ALOS PALSAR data needs to be focused because of the level of imagery at raw data. This focusing aims to register images with orbital parameters in the metadata. After focusing, an interferogram is generated. Next, the interferogram is carried out with adaptive filter and coherence. The results of this interferogram filter are used for phase unwrapping generation. The results obtained are phase unwrapping Fint, Dint, and Upha. Then the results of the unwrapping phase are carried out into refinement and re-flattening. The results are obtained in the form of phase unwrapping with minimum noise conditions. It is a more attractive appearance in limiting phases. This result is used for the next process. The process is the phase to height conversion or DSM extraction.

While in DSM conversion, height error correction was also performed with the relax interpolation and dummy interpolation approaches. The height reference field used is WGM 2012. Geoid undulation correction is carried out by transformed DSM to the height reference field of WGM 2012.

DTM will be obtained after the conversion has been done from DSM to DTM (Krauß \& Reinartz, 2007). This conversion is done by considering the vegetation coverage (tree cover) parameters, vegetation height offset, and the angle of the slope of the tree canopy. After obtaining the DTM, a vertical accuracy test is performed by comparing it with the results of height differences in ground measurements (Mukherjee et al., 2012). The accuracy test used is with a confidence level of $1.96 \sigma$. The results obtained are the corrected DTM or after this referred to as DTM master.

Sentinel-1 data 2018 and 2020 that were used to deformation generation (displacement). The processing method used is DInSAR (Ferretti et al., 2011; Koudogbo et al., 2019). DInSAR is a reduction of two topographies at a minimum of 2 time periods (Chang et al., 2019). If using many SAR data, we can use the Persistent Scatterer Interferometry (PS-InSAR) method to calculate the deformation (Hooper et al., 2012). The process is done by interferogram generation, adaptive filter, and coherence, phase unwrapping, refinement, and re-flattening. The filtered and corrected phase unwrapping results are used to calculate displacement (Ferretti et al., 2007). The result of this displacement is a vertical deformation that occurred from January 2018 to January 2020.

The latest DTM is obtained from the integration of the DTM master with displacement. The latest DTM can be updated based on the availability of the latest data following the specified time. If Sentinel-1 data can be obtained every 6 to 12 days, the latest DTM can be extracted every 6 to 12 days, at least one month. This paper is limited to reviewing a period of the latest DTM after obtaining a DTM master. The default of DTM master is the data 2017, while the updated of the latest DTM in Semangko fault is January 2020, see Eq. (1).
The latest DTM =
DTM master + the latest Displacement.

\subsection{Vertical accuracy test}

This paper discusses vertical accuracy using vertical accuracy and precision standards that refer to ASPRS Accuracy Data for Digital Geospatial Data, which is determined by the National Standard for Spatial Data Accuracy (NSSDA). Checking the vertical accuracy is done in two ways, namely (ASPRS, 2014):

a. Root Mean Square Error vertical $(R M S E(z))$

RMSE ( $z)$ is a height difference error that occurs at the entire measuring point, see Eq. (2):

$$
\operatorname{RMSE}(z)=\sqrt{\left(\frac{\sum\left(Z_{\text {Data }(i)-Z_{\text {Check }(i))^{2}}}\right)}{n}\right)} .
$$

In this case, $Z$ - height value; $n$ - number of measurement points; $Z_{\text {data }}-$ orthometric height on DTM; $Z_{\text {check }}-$ orthometric height measure.

Height measurement from the latest DTM is the comparison with field measurement from GNSS-leveling. The leveling measurement using the orthometric height system (Serrano-Juan et al., 2017). In this study, checking the vertical accuracy only involved vertical displacement. Horizontal displacement is not involved in calculating vertical accuracy.

b. Calculation of vertical accuracy at $95 \%$ confidence level $(1.96 \sigma)$. $\operatorname{Accuracy}(z)$ is a vertical accuracy value, see Eq. (3):

$$
\operatorname{Accuracy}(z)=1.96 \times \operatorname{RMSE}(z) \text {, }
$$

where the value of 1.96 is equal to the $95 \%$ confidence level.

\section{Results and discussion}

\subsection{Pre-processing and interferogram generation}

ALOS PALSAR data used is level 1.0 (raw data), which cannot be processed directly. This data needs to be preprocessed in the form of focusing. The results of this focusing can be used for Single Look Complex (SLC) generation data. This SLC is standard data in InSAR.

Before DSM extraction, using SAR data must consider the ambiguity height value $2 \pi$ (Liosis et al., 2018). If this value is significant $(>400 \mathrm{~m}$ ), the resulting DSM will be less useful. To get this condition, an attempt to use a data pair with a low height ambiguity value. Generally, the ALOS PALSAR data is more useful in DSM extraction and ground deformation in Indonesia's inactive fault regions (Lubis et al., 2011).

The theoretical height precision graph is a graph of the relationship between height ambiguation values and correlation values. This graph is used to calculate the data threshold in the phase to height and geocoding stages, see Figure 3. 


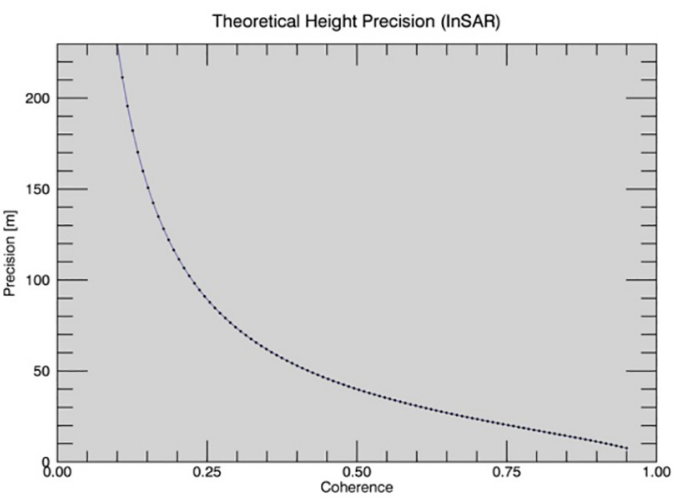

Figure 3. Theoretical height precision graph. $\mathrm{X}$ axis is coherence, $\mathrm{Y}$ axis is precision $(\mathrm{m})$

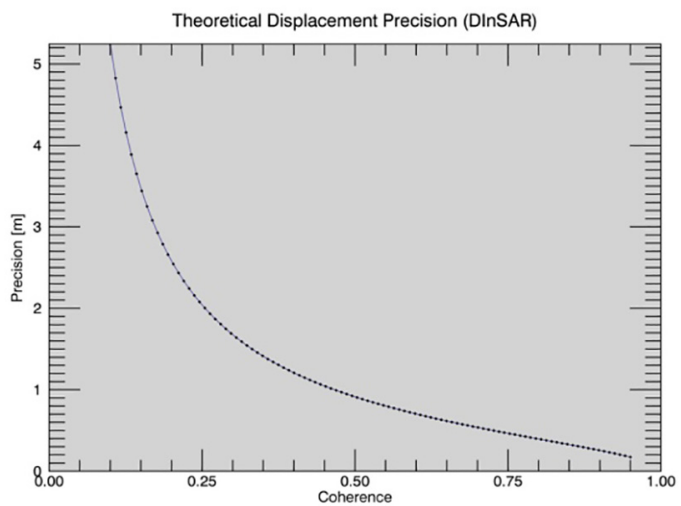

Figure 4. Theoretical displacement precision of DInSAR. $\mathrm{X}$ axis is coherence, $\mathrm{Y}$ axis is precision (m)

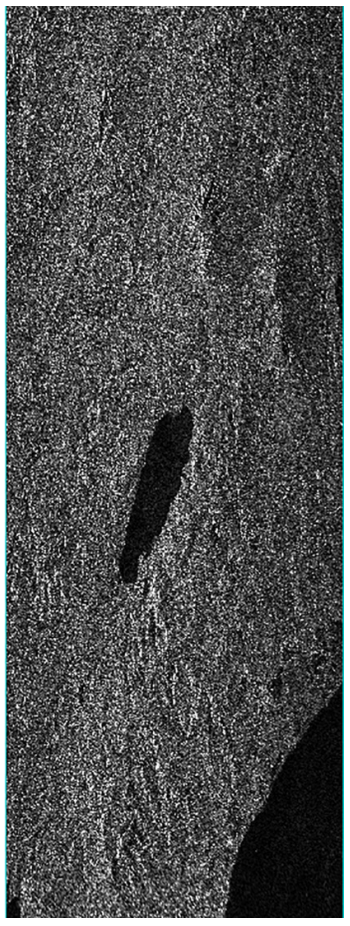

(a)

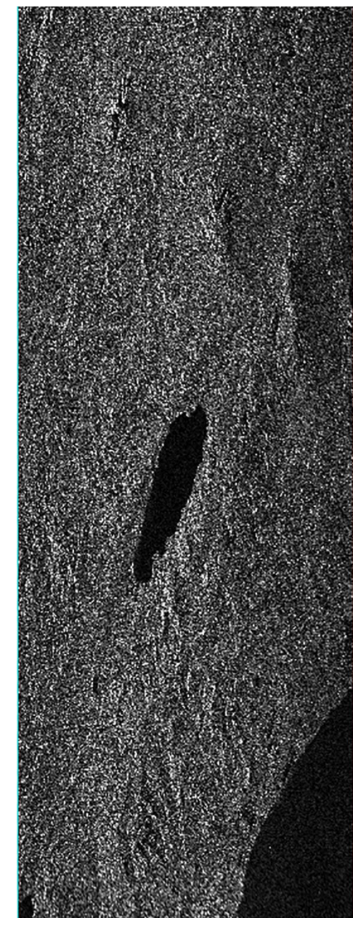

(b)
Figure 5. a - master image of ALOS PALSAR; b - slave image of ALOS PALSAR
The theoretical displacement precision of DInSAR graph used for checking SAR data is more suitable for DSM or displacement applications, see Figure 4. In displacement, extraction must consider the ambiguity height value $2 \pi$. If this value is significant $(>400 \mathrm{~m})$, the resulting displacement will be better (Costantini, 1998; Julzarika \& Harintaka, 2019). Sentinel-1 data is more suitable for displacement applications, especially in active fault areas in Indonesia. Sentinel-1 data is suitable for displacement applications (Rucci et al., 2012). Displacement on the Sentinel-1 is more directed at surface deformation (Caro Cuenca et al., 2013; Dias et al., 2018).

The image used for DSM extraction is the imagery in 2008 and 2017. The imagery in September 2008 is used as a master image, and the October 2008 imagery is used as a slave image, see Figure 5. The second condition, imagery in October 2017, is used as a master image, and the December 2017 imagery is used as a slave image. The image 2017 is used for DInSAR. The image 2008 is used for DSM. Those two images are integrated for DSM master. The two images with different acquisition performed focusing and interferogram generation. Indonesian DEMNAS is used for the height model approach (BIG, 2019). Focusing is done using orbit parameters and raw data images.

\subsection{Interferogram generation}

In displacement with Sentinel-1, the image used is in the form of SLC. It can be used for DInSAR applications. Both the master and slave image from ALOS PALSAR and Sentinel- 1 can be done by InSAR and DInSAR. The stages traversed in InSAR and DInSAR still have similarities, namely the interferogram generation, adaptive filter and coherence, phase unwrapping, refinement, and reflattening. The only difference is in the phase to height conversion and the phase to displacement conversion. Interferogram generation expressed master image and slave image are respectively, the imaginary and real parts of the interferogram, see Figure 6.

This interferogram will produce a coherence file (CC) between the master image and the slave image and

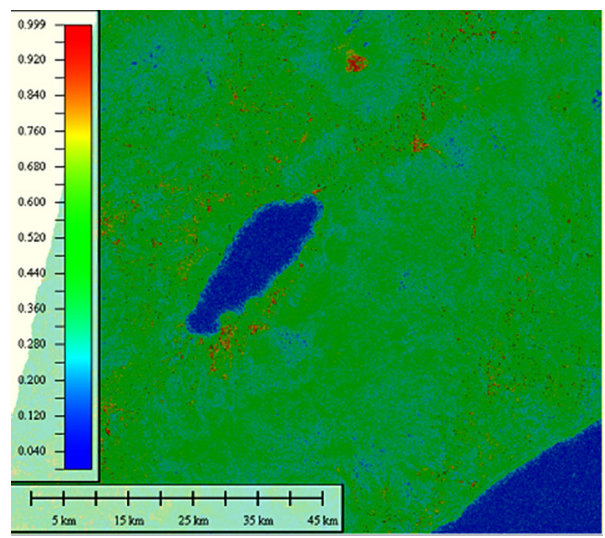

Figure 6. Interferogram of ALOS PALSAR 
topography approach, see Figure 6. This interferogram takes the azimuth look and range look values. On the value unwrapping coherence threshold, it uses the value (0.2) or can be changed by considering the theoretical height precision graph (Reigber \& Moreira, 1997). The method chosen in the unwrapping phase is the minimum cost flow, and to calculate the azimuth looks and range looks values, it can be done using the looks (multi looks) approach.

According to Figure 6, spectral shift and Doppler bandwidth filtering are common during interferogram

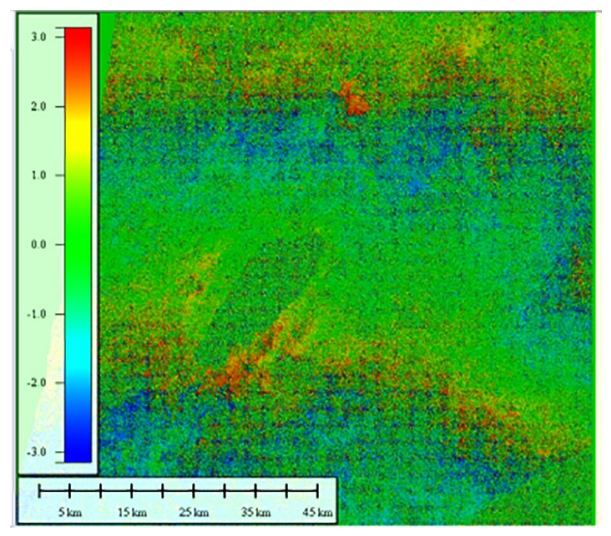

Figure 7. Phase unwrapping Dint

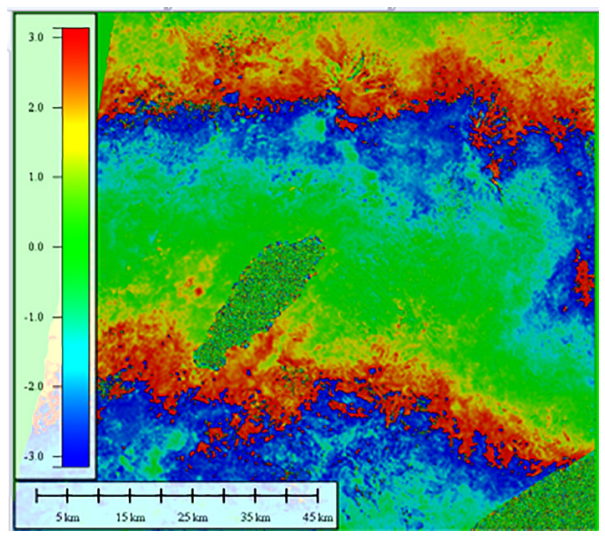

Figure 8. Phase unwrapping Fint

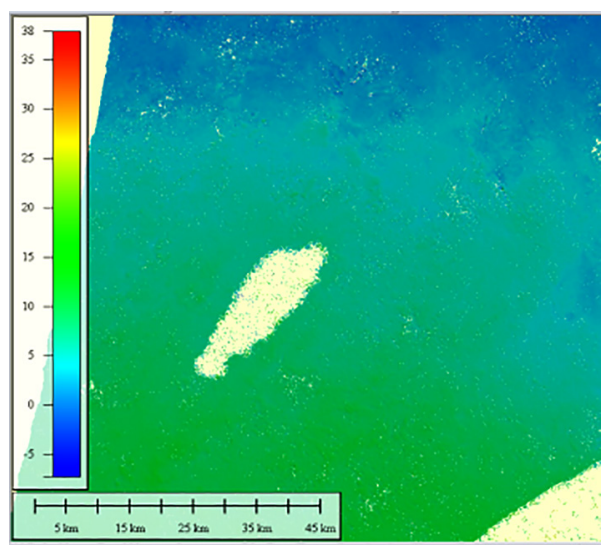

Figure 9. Phase unwrapping Upha generation. Doppler bandwidth filtering is needed to compensate for different Doppler (squint angle). The result is the azimuth spectrum shifting. The spectral shift is needed because of the shift in the spectrum of the range. It is caused by the perspective of the SAR variable on the target being distributed. The azimuth filter was applied to generate the interferogram. It will fully capture the potential coherence of the scene.

The reference DEM or the ellipsoidal model is used as the input in the interferogram flattening. It is used to correct the master image onto the DEM. The high accuracy and resolution of reference DEM will give a better result for topography removal. Interferogram flattening is done using the Indonesian DEMNAS as DEM reference input.

\subsection{Phase unwrapping}

This phase unwrapping produces three types of files, namely Fint and CC, Dint, and Upha. Interferograms and coherence are used in phase unwrapping generation. Dint is flattened interferogram, Fint is filtered interferogram, CC is coherence file, and Upha is an unwrapped phase. In Figure 7, phase unwrapping Dint is the result of phase unwrapping using an interferogram image and a coherence image (CC). In this phase, the filter has been carried out on the phase unwrapping Dint data. The results of phase unwrapping Dint still have much noise. Phase unwrapping Fint must be done to solve this noise. Phase unwrapping Fint is obtained from interferometry with a minimum cost flow method with unwrapping coherence threshold value of 0.2 (Reigber \& Moreira, 1997).

Phase unwrapping Fint describes the changing (deformation) on the north and south sides of Lake Singkarak, see Figure 8. The northern side dominates change. The unwrapping phase uses the unit in $\pi$.

Phase unwrapping Upha is the final result in the phase unwrapping. This data is used for refinement and re-flattening. The results of the phase unwrapping Upha can be seen in Figure 9.

\subsection{Refinement and re-flattening}

Refinement and re-flattening. This stage is a very crucial stage to correct the transformation of the phase unwrapping. At this stage, the satellite orbit is corrected, and the phase offset is calculated. The result of the refinement and re-flattening can be seen in Figure 10.

\subsection{DSM}

The phase to height conversion is the last process in InSAR. The result of the InSAR is DSM. In this step, it is also using height error correction. It uses relax interpolation and dummy interpolation. Figure 11 is the DSM from phase to height conversion that has height error correction.

This DSM conversion is after this referred to as DTM master. This conversion is obtained from the use of offset parameters for vegetation height, orthometric height, and slope between vegetation to ground, see Figure 12. 


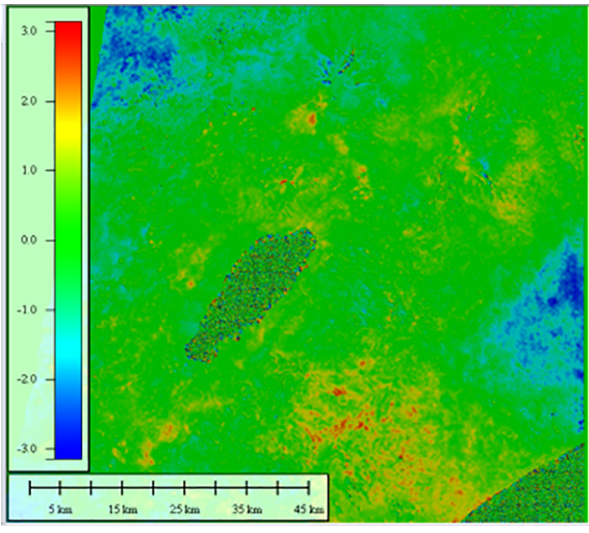

Figure 10. Refinement and re-flattening

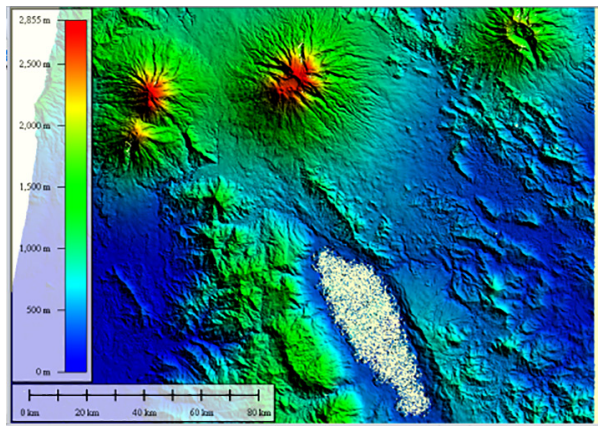

Figure 11. DSM from phase to height conversion

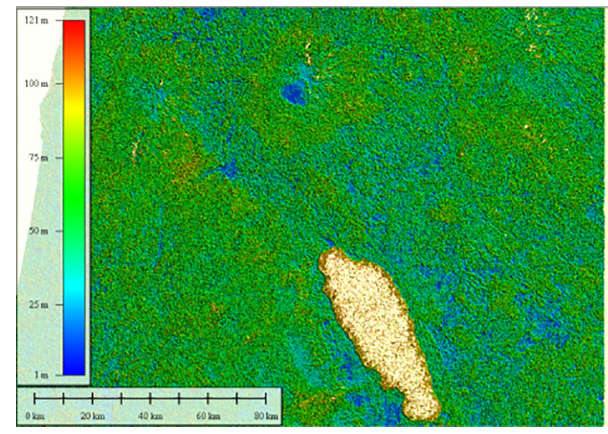

Figure 12. DSM conversion (vegetation height)

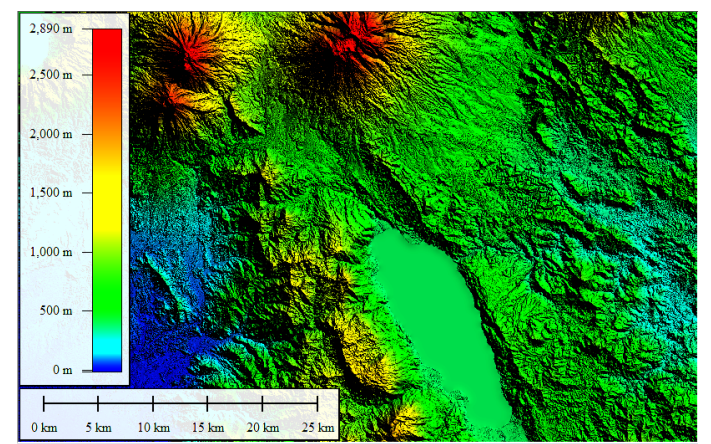

Figure 13. DTM master
DTM master is a DTM that is used as a reference in making the latest DTM. The DTM master has a deadline for construction until the end of December 2017. In this region, the elevation is between 0 to $2,855 \mathrm{~m}$. On the north side of Lake Singkarak, there is a fault line that extends to the north side. This line is the Semangko fault. Lake Singkarak elevation is made into no data or equated with the elevation of the Lake Singkarak. Figure 13 is the DTM master.

\subsection{Displacement}

Displacement was obtained from DInSAR from Sentinel-1 imagery, see Figure 14.

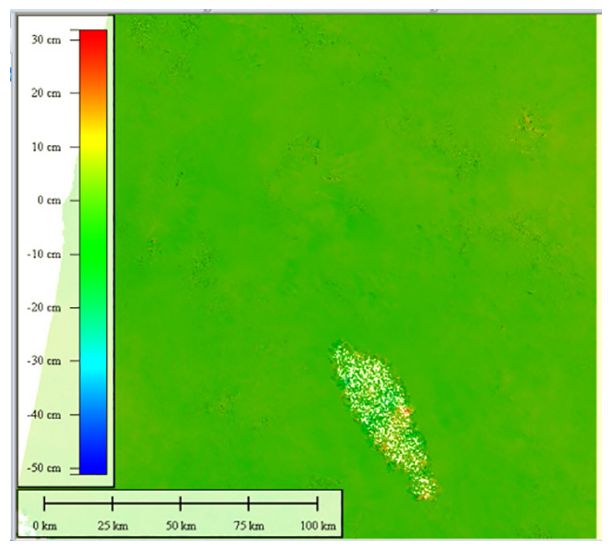

Figure 14. Displacement from Sentinel-1

The study area has vertical deformation or displacement at a value of $-50 \mathrm{~cm}$ to $30 \mathrm{~cm}$. The displacement in Semangko fault area is dominated by $-25 \mathrm{~cm}$ to $5 \mathrm{~cm}$. In general, this region has decreased. The decline in this region ranges from $7.5 \mathrm{~cm}$ to $10 \mathrm{~cm}$ per year. This reduction has not taken into account the parameters of the earthquake and landslides.

\subsection{The latest DTM}

The latest DTM is an upgradable DTM obtained from the combined deformation and DTM master. This research uses the vertical direction (1D) displacement. The latest DTM generated depicts dynamic displacement with vertical accuracy following the DTM master. The latest DTM describes the latest conditions that occur in the study area.

As for the development of DTM integration and deformation methods from Sentinel-1, the latest DTM vertical accuracy is obtained with a scale of $1: 10,000$ to $1: 20,000$ and with higher vertical accuracy than static DTMs.

The yellow line is the Semangko fault. This line is used to check the condition of the longitudinal profile in Semangko fault. The elevation value of this fault is located at 240 to $1,250 \mathrm{~m}$, see Figure 15. In some areas or around a distance of 20 to $40 \mathrm{~km}$ from the starting point of the line. It was passing through the steep hills. This area has many cliffs in the longitudinal profile, see Figure 16. 


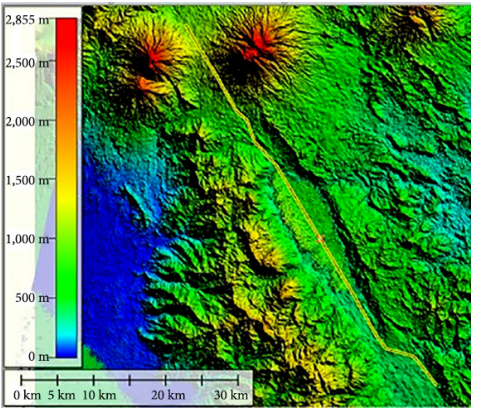

Figure 15. The latest DTM and Semangko fault line

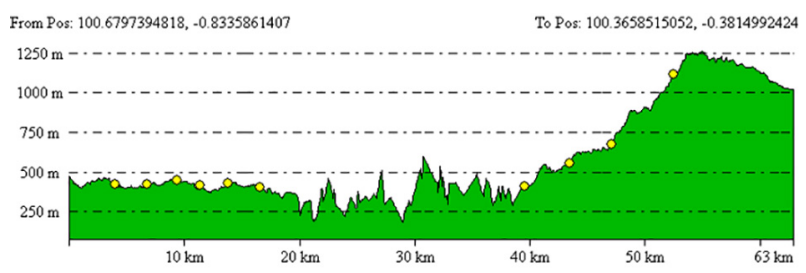

Figure 16. Longitudinal profile along the Semangko fault

The latest DTM can be used in monitoring the dynamics of the Semangko fault. DTM is generated using DTM master and displacement. DTM master in 2017 first performed an accuracy test that met the tolerance of $1.96 \sigma(95 \%)$. Vertical accuracy test using 10 test points, see Table 1.

Table 1. comparison height difference between the latest DTM and field measurements

\begin{tabular}{|c|c|c|c|c|c|}
\hline No & $\mathrm{X}(\mathrm{m})$ & $\mathrm{Y}(\mathrm{m})$ & $\mathrm{h}(\mathrm{m})$ & $\mathrm{H}(\mathrm{m})$ & $\Delta \mathrm{h}(\mathrm{m})$ \\
\hline t01 & 665,575 & $9,941,652$ & 373.87 & 377.91 & 4.0367 \\
\hline t02 & 665,595 & $9,941,683$ & 377.08 & 377.84 & 0.758 \\
\hline t03 & 665,582 & $9,941,706$ & 377.05 & 377.77 & 0.715 \\
\hline t04 & 665,567 & $9,941,739$ & 379.19 & 378.10 & -1.086 \\
\hline t05 & 665,566 & $9,941,768$ & 378.58 & 378.02 & -0.563 \\
\hline t06 & 665,591 & $9,941,787$ & 379.03 & 378.08 & -0.948 \\
\hline t07 & 665,618 & $9,941,790$ & 379.56 & 379.18 & -0.390 \\
\hline t08 & 665,639 & $9,941,787$ & 378.97 & 379.83 & 0.867 \\
\hline t09 & 665,650 & $9,941,808$ & 379.11 & 382.75 & 3.636 \\
\hline t10 & 665,668 & $9,941,821$ & 382.69 & 386.67 & 3.985 \\
\hline & & & $R M S E(z)$ & 1.101 \\
\hline
\end{tabular}

The Root Mean Square Error (RMSE) $(z)$ between the field and the latest DTM is $1.101 \mathrm{~m}$. Based on the RMSE $(z)$ obtained, the latest DTM vertical accuracy is $2.158 \mathrm{~m}$ at the $95 \%$ confidence level. The vertical accuracy value corresponds to a mapping scale of 1:10,000 to 1:20,000. Field measurements are from GNSS-leveling data. The comparison height difference is only using vertical displacement. It does not use horizontal displacement. Measurements were made in a relatively flat area. The measurement location on the roadside is near the Semangko fault. Measurements in high regions cannot be done yet because of limited tools, steep and challenging terrain. $\mathrm{X}$ and $\mathrm{Y}$ are Universal Transverse Mercator (UTM) Cartesian coordinate. $\mathrm{h}$ is the elevation in the latest DTM, H is the elevation in field measurement, and $\Delta \mathrm{h}$ is the height difference between the latest DTM and field measurement.

The DTM master that has met the vertical accuracytest requirements adds to the displacement obtained from Sentinel-1. The dynamics of the Semangko fault obtained by this latest DTM change from 2018 to 2020. Figure 17 is the latest DTM in Semangko fault (northern Lake Singkarak), 2020.

Based on the latest DTM, this Semangko Fault area has experienced displacement (decrease), see Figure 18.

The purple line is the elevation in 2020, the blue line was the elevation in 2017, and the red line was the elevation in 2008. This coordinate is around the Semangko fault center. This location ever has landslide when a vertical earthquake. In Figure 18, we can see a vertical change in one of the areas in the center of the Semangko fault. DTM in 2008, 2017, 2020 has decreased. Higher declines occurred between 2008 to 2017. This condition is likely due to landslides and earthquakes in this region. One of the biggest earthquakes that occurred was a vertical earthquake on 30 September 2009 with a magnitude of 7.6 Mw.

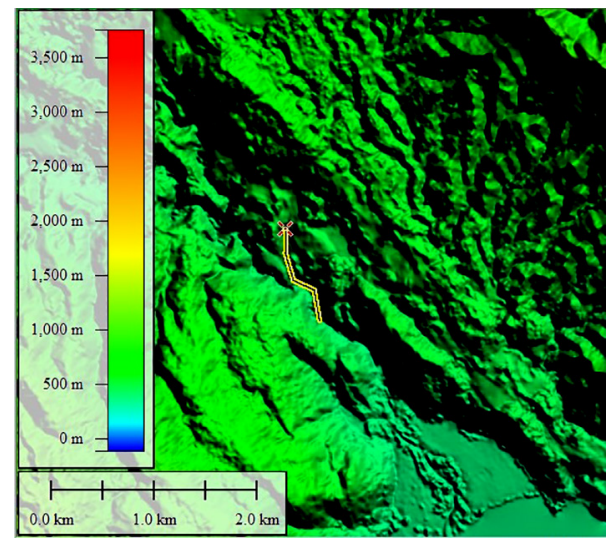

Figure 17. The latest DTM in Semangko fault in 2020

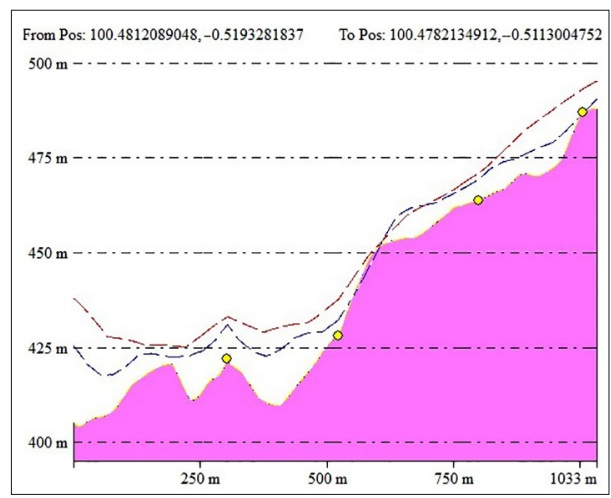

Figure 18. The change in Semangko fault using the longitudinal profile (northern Lake Singkarak) 


\section{Conclusions}

The latest DTM is an upgradable DTM obtained from the combined deformation and DTM master to detect the dynamics of Semangko's fault. This research analyzes displacement into vertical direction (1D). The latest DTM vertical accuracy is $2.158 \mathrm{~m}$ at the $95 \%$ confidence level. It is obtained with a scale of $1: 10,000$ to $1: 20,000$. The vertical accuracy of the latest DTM is higher than static DTMs. Furthermore, it has vertical deformation or displacement at a value of $-50 \mathrm{~cm}$ to $30 \mathrm{~cm}$. The Semangko fault area is dominated by $-25 \mathrm{~cm}$ to $5 \mathrm{~cm}$ deformation. In general, this region has decreased into $7.5 \mathrm{~cm}$ to $10 \mathrm{~cm}$ per year. This condition is likely due to landslides and earthquake in this region. One of the biggest earthquakes that occurred was a vertical earthquake on 30 September 2009 with a magnitude of 7.6 Mw.

\section{Acknowledgements}

Thanks to Alaska University and JAXA for the ALOS PALSAR data. Thanks to ESA for Sentinel-1 data, Universitas Gadjah Mada and LAPAN for supporting this research.

\section{Authors' note}

The authors declare that there is no conflict of interest regarding the publication of this article. The authors confirmed that the data and the paper are free of plagiarism.

\section{References}

Alganci, U., Besol, B., \& Sertel, E. (2018). Accuracy assessment of different digital surface models. ISPRS International Journal of Geo-Information, 7(3), 114.

https://doi.org/10.3390/ijgi7030114

Arai, Y. (2019). Pre-treatment for preventing degradation of measurement accuracy from speckle noise in speckle interferometry. Measurement, 136, 36-41.

https://doi.org/10.1016/j.measurement.2018.10.046

Arefi, H., d'Angelo, P., Mayer, H., \& Reinartz, P. (2009). Automatic generation of digital terrain models from Cartosat- 1 stereo images. In ISPRS workshop Hannover 2009, 83(1-4-7), 1-6. https://www.isprs.org/PROCEEDINGS/XXXVIII/1_4_7-W5/ paper/Arefi-169.pdf

ASPRS. (2014). ASPRS Accuracy standards for Digital Geospatial Data. The American Society for Photogrammetry and Remote Sensing. http://www.asprs.org/a/society/divisions/ pad/Accuracy/Draft_ASPRS_Accuracy_Standards_for_Digital_Geospatial_Data_PE\&RS.pdf

Bakon, M., Perissin, D., Lazecky, M., \& Papco, J. (2014). Infrastructure non-linear deformation monitoring via satellite radar interferometry. Procedia Technology, 16, 294-300. https://doi.org/10.1016/j.protcy.2014.10.095

Bayoud, F. A., \& Sideris, M. G. (2003). Two different methodologies for geoid determination from ground and airborne gravity data. Geophysical Journal International, 155(3), 914-922. https://doi.org/10.1111/j.1365-246X.2003.02083.x

Badan Informasi Geospasial. (2019). DEMNAS. http://tides.big.go.id/DEMNAS/

Bigdeli, B., Amini Amirkolaee, H., \& Pahlavani, P. (2018). DTM extraction under forest canopy using LiDAR data and a mod- ified invasive weed optimization algorithm. Remote Sensing of Environment, 216, 289-300.

https://doi.org/10.1016/j.rse.2018.06.045

Bonvalot, S., Balmino, G., Briais, A., Kuhn, M., Peyrefitte, A., Vales, N., \& Biancale, R. (2012). World Gravity Map: a set of global complete spherical Bouguer and isostatic anomaly maps and grids. Geophysical Research Abstracts, 14, 11091. https://meetingorganizer.copernicus.org/EGU2012/ EGU2012-11091.pdf

Caro Cuenca, M., Hooper, A. J., \& Hanssen, R. F. (2013). Surface deformation induced by water influx in the abandoned coal mines in Limburg, The Netherlands observed by satellite radar interferometry. Journal of Applied Geophysics, 88, 1-11. https://doi.org/10.1016/j.jappgeo.2012.10.003

Champion, N., \& Boldo, D. (2006). A robust algorithm for estimating digital terrain models from digital surface models in dense urban areas. In Proceedings ISPRS Commission 3 Symposium, Photogrammetric Computer Vision. https://www.isprs. org/proceedings/xxxvi/part3/singlepapers/O_09.pdf

Chang, L., Ku, O., \& Hanssen, R. F. (2019). Identification of deformation pattern changes caused by enhanced oil recovery (EOR) using InSAR. International Journal of Remote Sensing, 40(4), 1495-1505.

https://doi.org/10.1080/01431161.2018.1526426

Costantini, M. (1998). A novel phase unwrapping method based on network programming. IEEE Transactions on Geoscience and Remote Sensing, 36(3), 813-821. https://doi.org/10.1109/36.673674

Cuevas-González, M., Crosetto, M., Monserrat, O., \& Crippa, B. (2018). Sentinel-1A/B imagery for terrain deformation monitoring: a strategy for Atmospheric Phase Screening (APS) estimation. Procedia Computer Science, 138, 388-392. https://doi.org/10.1016/j.procs.2018.10.055

Dai, K., Li, Z., Tomás, R., Liu, G., Yu, B., Wang, X., Cheng, H., Chen, J., \& Stockamp, J. (2016). Monitoring activity at the Daguangbao mega-landslide (China) using Sentinel-1 TOPS time series interferometry. Remote Sensing of Environment, 186, 501-513. https://doi.org/10.1016/j.rse.2016.09.009

Dammann, D. O., Eicken, H., Meyer, F. J., \& Mahoney, A. R. (2016). Assessing small-scale deformation and stability of landfast sea ice on seasonal timescales through L-band SAR interferometry and inverse modeling. Remote Sensing of Environment, 187, 492-504. https://doi.org/10.1016/j.rse.2016.10.032

Dias, P., Catalao, J., \& Marques, F. O. (2018). Sentinel-1 InSAR data applied to surface deformation in Macaronesia (Canaries and Cape Verde). Procedia Computer Science, 138, 382-387. https://doi.org/10.1016/j.procs.2018.10.054

Du, Z., Ge, L., Ng, A. H.-M., Zhu, Q., Yang, X., \& Li, L. (2018). Correlating the subsidence pattern and land use in Bandung, Indonesia with both Sentinel-1/2 and ALOS-2 satellite images. International Journal of Applied Earth Observation and Geoinformation, 67, 54-68. https://doi.org/10.1016/j.jag.2018.01.001

EORC-JAXA. (2021). ALOS research and application project. https://www.eorc.jaxa.jp/ALOS/a/en/index_e.htm

European Space Agency. (2019). Sentinel satellites. https://www. esa.int/Our_Activities/Observing_the_Earth/Copernicus/ Overview4

Ferretti, A., Fumagalli, A., Novali, F., Prati, C., Rocca, F., \& Rucci, A. (2011). A new algorithm for processing interferometric data-stacks: SqueeSAR. IEEE Transactions on Geoscience and Remote Sensing, 49(9), 3460-3470. https://doi.org/10.1109/TGRS.2011.2124465 
Ferretti, A., Monti-Guarnieri, A., Prati, C., \& Fabio, R. (2007). InSAR principles: Guidelines for SAR interferometry processing and interpretation (TM-19). European Space Agency. https://www.esa.int/esapub/tm/tm19/TM-19_ptA.pdf

Gallant, J. C., Read, A. M., \& Dowling, T. I. (2012). Removal of tree offsets from SRTM and other digital surface models. ISPRS - International Archives of the Photogrammetry, Remote Sensing and Spatial Information Sciences, XXXIXB4(September), 275-280.

https://doi.org/10.5194/isprsarchives-XXXIX-B4-275-2012

Geological. (2017). Sesar Semangko. http://geologicalmelankolia. blogspot.com/2017/03/sesar-semangko-sumatera.html

Hirt, C. (2014). Encyclopedia of geodesy. Springer. https://doi.org/10.1007/978-3-319-02370-0

Hofmann-Wellenhof, B., \& Moritz, H. (2006). Physical geodesy (2nd ed.). Springer.

https://doi.org/10.1007/978-3-211-33545-1

Hooper, A., Bekaert, D., Spaans, K., \& Arikan, M. (2012). Recent advances in SAR interferometry time series analysis for measuring crustal deformation. Tectonophysics, 514-517, 1-13. https://doi.org/10.1016/j.tecto.2011.10.013

Hurukawa, N., Wulandari, B. R., \& Kasahara, M. (2014). Earthquake history of the Sumatran fault, Indonesia, since 1892, derived from relocation of large earthquakes. Bulletin of the Seismological Society of America, 104(4), 1750-1762. https://doi.org/10.1785/0120130201

JAXA. (2008). ALOS data users handbook. Revision C. http://www.eorc.jaxa.jp/ALOS/en/doc/fdata/ALOS_HB_ RevC_EN.pdf

Julzarika, A. (2015). Height model integration using ALOS PALSAR, X SAR, SRTM C, and IceSAT/GLAS. International Journal of Remote Sensing and Earth Sciences, 12(2), 107-116. https://doi.org/10.30536/j.ijreses.2015.v12.a2691

Julzarika, A., \& Djurdjani, D. (2018). DEM classifications: opportunities and potential of its applications. Journal of Degraded and Mining Lands Management, 5(53).

https://doi.org/10.15243/jdmlm.2019.064.1897

Julzarika, A., \& Harintaka. (2019). Utilization of sentinel satellite for vertical deformation monitoring in Semangko FAULTIndonesia. In The 40th Asian Conference on Remote Sensing (ACRS 2019) (pp. 1-7).

https://a-a-r-s.org/proceeding/ACRS2019/WeA2-3.pdf

Julzarika, A., \& Harintaka. (2020). Indonesian DEMNAS: DSM or DTM? In 2019 IEEE Asia-Pacific Conference on Geoscience, Electronics and Remote Sensing Technology (AGERS) (pp. 31-36). IEEE.

https://doi.org/10.1109/AGERS48446.2019.9034351

Julzarika, A., \& Rokhmana, C. A. (2019). Detection of vertical deformation in Jakarta-Bandung high speed train route using $\mathrm{X}$ sar and sentinel. Geodesy and Cartography, 45(4), 169-176. https://doi.org/10.3846/gac.2019.10761

Katili, J. A. (1967). On the occurrence of Large Transcurrent Faults in Sumatra, Indonesia. Journal of Geosciences Osaka City University, 10, 5-17.

http://ci.nii.ac.jp/naid/10012396688/en/

Koudogbo, F., Urdiroz, A., Robles, J. G., \& Chapron, G. (2019). Radar interferometry as an innovative solution for monitoring the construction of the Grand Paris Express metro network - First results. In INSAR Paper-Tre Altamira.

https://site.tre-altamira.com/wp-content/uploads/2018_InSAR_monitoring_Grand-Paris-Express-metro-construction_ Koudogbo_et_al_WTC2018.pdf.

Koukouvelas, I. K., Zygouri, V., Nikolakopoulos, K., \& Verroios, S. (2018). Treatise on the tectonic geomorphology of active faults: The significance of using a universal digital elevation model. Journal of Structural Geology, 116, 241-252. https://doi.org/10.1016/j.jsg.2018.06.007

Krauß, T. (2018). A new simplified DSM-to-DTM algorithm dsm-to-dtm-step. Preprints. https://doi.org/10.20944/preprints201807.0017.v1

Krauß, T., Arefi, H., \& Reinartz, P. (2011). Evaluation of selected methods for extracting digital terrain models from satellite born digital surface models in urban areas. In SMPR 2011, (pp. 1-7). https://elib.dlr.de/72731/

Krauß, T., \& Reinartz, P. (2007). Urban object detection using a fusion approach of dense urban digital surface models and VHR optical satellite stereo data. ISPRS Istanbul Workshop 2010 on Modeling of Optical Airborne and Spaceborne Sensors, 38, 13-18. https://www.isprs.org/proceedings/xxxviii/1W17/1_krauss.pdf

Lesko, M., Papco, J., Bakon, M., \& Liscak, P. (2018). Monitoring of natural hazards in Slovakia by using of satellite radar interferometry. Procedia Computer Science, 138, 374-381. https://doi.org/10.1016/j.procs.2018.10.053

Li, L., \& Kuai, X. (2014). An efficient dichotomizing interpolation algorithm for the refinement of TIN-based terrain surface from contour maps. Computers and Geosciences, 72, 105-121. https://doi.org/10.1016/j.cageo.2014.07.001

Li, Z., Zhu, Q., \& Gold, C. (2004). Digital terrain modeling: Principles and methodology. CRC Press.

https://doi.org/10.1201/9780203357132

Liosis, N., Marpu, P. R., Pavlopoulos, K., \& Ouarda, T. B. M. J. (2018). Ground subsidence monitoring with SAR interferometry techniques in the rural area of Al Wagan, UAE. Remote Sensing of Environment, 216, 276-288.

https://doi.org/10.1016/j.rse.2018.07.001

Liu, C. L., Gao, X. Z., Jiang, W. D., \& Li, X. (2011). Intergerometric ISAR three-dimensional imaging using one antenna. Progress in Electromagnetics Research M, 21, 33-45. https://doi.org/10.2528/PIERM11070803

Liu, Y., Zhao, C., Zhang, Q., \& Yang, C. (2018). Complex surface deformation monitoring and mechanism inversion over Qingxu-Jiaocheng, China with multi-sensor SAR images. Journal of Geodynamics, 114, 41-52. https://doi.org/10.1016/j.jog.2018.01.016

Lubis, A. M., Sato, T., Tomiyama, N., Isezaki, N., \& Yamanokuchi, T. (2011). Ground subsidence in Semarang-Indonesia investigated by ALOS-PALSAR satellite SAR interferometry. Journal of Asian Earth Sciences, 40(5), 1079-1088. https://doi.org/10.1016/j.jseaes.2010.12.001

Lusch, D. P. (1999). Introdcution to microwave remote sensing. The Photogrammetric Record, 24(126), 199. https://doi.org/10.1111/j.1477-9730.2009.00531_1.x

Maune, D. F., \& Nayegandhi, A. (2018). Digital elevation model technologies and applications: The DEM users manual. American Society for Photogrammetry and Remote Sensing.

Monserrat, O., Crosetto, M., \& Luzi, G. (2014). A review of ground-based SAR interferometry for deformation measurement. ISPRS Journal of Photogrammetry and Remote Sensing, 93, 40-48. https://doi.org/10.1016/j.isprsjprs.2014.04.001

Moudrý, V., Lecours, V., Gdulová, K., Gábor, L., Moudrá, L., Kropáček, J., \& Wild, J. (2018). On the use of global DEMs in ecological modelling and the accuracy of new bare-earth DEMs. Ecological Modelling, 383, 3-9. https://doi.org/10.1016/j.ecolmodel.2018.05.006

Mukherjee, S., Joshi, P. K., Mukherjee, S., Ghosh, A., Garg, R. D., \& Mukhopadhyay, A. (2012). Evaluation of vertical accuracy of open source Digital Elevation Model (DEM). International 
Journal of Applied Earth Observation and Geoinformation, 21(1), 205-217. https://doi.org/10.1016/j.jag.2012.09.004

Nahli, A., Durand, E., Rangeard, D., \& Rangeard, D. (2018). Sentinel-1 for monitoring tunnel excavations in Rennes, France. Procedia Computer Science, 138, 393-400. https://doi.org/10.1016/j.procs.2018.10.056

Naidoo, L., Mathieu, R., Main, R., Wessels, K., \& Asner, G. P. (2016). L-band Synthetic Aperture Radar imagery performs better than optical datasets at retrieving woody fractional cover in deciduous, dry savannahs. International Journal of Applied Earth Observation and Geoinformation, 52, 54-64. https://doi.org/10.1016/j.jag.2016.05.006

Natawidjaja, D. H. (2018). Updating active fault maps and sliprates along the Sumatran Fault Zone, Indonesia. IOP Conference Series: Earth and Environmental Science, 118(1), 012001. https://doi.org/10.1088/1755-1315/118/1/012001

Ng, A. H.-M., Ge, L., Du, Z., Wang, S., \& Ma, C. (2017). Satellite radar interferometry for monitoring subsidence induced by longwall mining activity using Radarsat-2, Sentinel-1 and ALOS-2 data. International Journal of Applied Earth Observation and Geoinformation, 61, 92-103.

https://doi.org/10.1016/j.jag.2017.05.009

Passchier C. W., \& Trouw R. A. J. (2005). Micro-tectonics. Springer.

Pieraccini, M., \& Miccinesi, L. (2019). Ground-based radar interferometry: A bibliographic review. Remote Sensing, 11(9). https://doi.org/10.3390/rs11091029

Pirotti, F. (2010). Assessing a template matching approach for tree height and position extraction from lidar-derived canopy height models of Pinus pinaster stands. Forests, 1(4), 194-208. https://doi.org/10.3390/f1040194

Quiroga, J. A., Servin, M., \& Cuevas, F. (2002). Modulo $2 \pi$ fringe orientation angle estimation by phase unwrapping with a regularized phase tracking algorithm. Journal of the Optical Society of America A, 19(8), 1524. https://doi.org/10.1364/josaa.19.001524

Raaflaub, L. D., \& Collins, M. J. (2006). The effect of error in gridded digital elevation models on the estimation of topographic parameters. Environmental Modelling and Software, 21(5), 710-732. https://doi.org/10.1016/j.envsoft.2005.02.003

Reigber, A., \& Moreira, J. (1997). Phase unwrapping by fusion of local and global methods. In IGARSS'97. 1997 IEEE International Geoscience and Remote Sensing Symposium Proceedings. Remote Sensing - A Scientific Vision for Sustainable Development (Vol. 2, pp. 869-871). IEEE.

https://doi.org/10.1109/IGARSS.1997.615282

Rucci, A., Ferretti, A., Monti Guarnieri, A., \& Rocca, F. (2012). Sentinel 1 SAR interferometry applications: The outlook for sub millimeter measurements. Remote Sensing of Environment, 120, 156-163. https://doi.org/10.1016/j.rse.2011.09.030
Serrano-Juan, A., Pujades, E., Vázquez-Suñè, E., Crosetto, M., \& Cuevas-González, M. (2017). Leveling vs. InSAR in urban underground construction monitoring: Pros and cons. Case of la sagrera railway station (Barcelona, Spain). Engineering Geology, 218, 1-11. https://doi.org/10.1016/j.enggeo.2016.12.016

Socquet, A., Hollingsworth, J., Pathier, E., \& Bouchon, M. (2019). Evidence of supershear during the 2018 magnitude 7.5 Palu earthquake from space geodesy. Nature Geoscience, 12, 192199. https://doi.org/10.1038/s41561-018-0296-0

Strozzi, T., Klime, J., Frey, H., Cadu, R., Huggel, C., \& Wegmüller, U. (2018). Remote Sensing of Environment Satellite SAR interferometry for the improved assessment of the state of activity of landslides: A case study from the Cordilleras of Peru. Remote Sensing of Environment, 217, 111-125. https://doi.org/10.1016/j.rse.2018.08.014

Turcotte, D., \& Schubert, G. (2014). Geodynamics. Cambridge University Press. https://doi.org/10.1017/CBO9780511843877

Wang, B., Shi, W., \& Liu, E. (2015). Robust methods for assessing the accuracy of linear interpolated DEM. International Journal of Applied Earth Observation and Geoinformation, 34(1). https://doi.org/10.1016/j.jag.2014.08.012

Wang, Q. J., Li, Z. W., Du, Y. N., Xie, R. A., Zhang, X. Q., Jiang, M., \& Zhu, J. J. (2014). Generalized functional model of maximum and minimum detectable deformation gradient for PALSAR interferometry. Transactions of Nonferrous Metals Society of China (English Edition), 24(3), 824-832. https://doi.org/10.1016/S1003-6326(14)63132-0

Weidner, U., \& Förstner, W. (1995). Towards automatic building extraction from high-resolution digital elevation models. ISPRS Journal of Photogrammetry and Remote Sensing, 50(4), 38-49. https://doi.org/10.1016/0924-2716(95)98236-S

Xin, X., Liu, B., Di, K., Jia, M., \& Oberst, J. (2018). High-precision co-registration of orbiter imagery and digital elevation model constrained by both geometric and photometric information. ISPRS Journal of Photogrammetry and Remote Sensing, 144, 28-37. https://doi.org/10.1016/j.isprsjprs.2018.06.016

Zhang, Y., Zhang, Y., Zhang, Y., \& Li, X. (2016). Automatic extraction of DTM from low resolution DSM by two steps semiglobal filtering. ISPRS Annals of the Photogrammetry, Remote Sensing and Spatial Information Sciences, 3, 249-255. https://doi.org/10.5194/isprs-annals-III-3-249-2016

Zuo, R., Qu, C., Shan, X., Zhang, G., \& Song, X. (2016). Tectonophysics Coseismic deformation fields and a fault slip model for the Mw7.8 mainshock and Mw7.3 aftershock of the Gorkha-Nepal 2015 earthquake derived from Sentinel-1A SAR interferometry. Tectonophysics, 686, 158-169. https://doi.org/10.1016/j.tecto.2016.07.032 